\title{
Educational Psychology
}

\section{Begin-of-school-year perceived autonomy-support and structure as predictors of end-of-school-year study efforts and procrastination: the mediating role of autonomous and controlled motivation}

\author{
A. Mouratidis, A. Michou, N. Aelterman, L. Haerens \& M. Vansteenkiste
}

To cite this article: A. Mouratidis, A. Michou, N. Aelterman, L. Haerens \& M. Vansteenkiste (2018) Begin-of-school-year perceived autonomy-support and structure as predictors of end-of-schoolyear study efforts and procrastination: the mediating role of autonomous and controlled motivation, Educational Psychology, 38:4, 435-450, DOI: 10.1080/01443410.2017.1402863

To link to this article: https://doi.org/10.1080/01443410.2017.1402863

Published online: 17 Nov 2017.

Џ Article views: 92
Submit your article to this journal $₫$ 


\title{
Begin-of-school-year perceived autonomy-support and structure as predictors of end-of-school-year study efforts and procrastination: the mediating role of autonomous and controlled motivation
}

\author{
A. Mouratidis ${ }^{a}$ (D) A. Michou ${ }^{b}$, N. Aelterman ${ }^{c}$, L. Haerens ${ }^{d}$ and M. Vansteenkiste ${ }^{c}$ \\ ${ }^{\mathrm{a} D e p a r t m e n t ~ o f ~ P s y c h o l o g y, ~ T E D ~ U n i v e r s i t y, ~ A n k a r a, ~ T u r k e y ; ~}{ }^{\mathrm{b}}$ Graduate School of Education, Bilkent University, \\ Ankara, Turkey; 'Department of Developmental, Personality and Social Psychology, Ghent University, Gent, \\ Belgium; 'Department of Movement and Sports Sciences, Ghent University, Gent, Belgium
}

\begin{abstract}
In this prospective study, we recruited a sample of Belgian adolescents $(N=886)$ to investigate to what extent perceived teachers' motivating style relates to quality of motivation in the beginning of the school year and, in turn, changes in study effort and procrastination by the end of the school year. After controlling for initial levels of study effort and procrastination and for a shared variance due to classroom membership, we found, through path analysis, perceived autonomy support and structure to relate positively to autonomous motivation, which in turn predicted increased study effort and decreased procrastination at the end of the school year. The findings are discussed from a theoretical and practical standpoint.
\end{abstract}

\section{ARTICLE HISTORY}

Received 19 January 2017

Accepted 6 November 2017

\section{KEYWORDS}

Self-determination; learning environment; adolescence; learning strategies; path analysis

Most educators would agree that some adolescents may postpone their assigned school work and avoid putting forth effort when doing their homework. Apparently, students' motivation to do their homework can largely explain whether they may behave in this way. While some students may study because they find the learning content enjoyable, interesting, and valuable (i.e. they are autonomously motivated), others may feel rather compelled to do so (i.e. they are controlled motivated). Research conducted under the framework of SelfDetermination Theory (SDT; Deci \& Ryan, 2000; Ryan \& Deci, 2017) has indicated that the more students are autonomously motivated, the more they thrive, as indexed by greater engagement and effort-expenditure, better learning, and higher achievement (e.g. Guay, Ratelle, \& Chanal, 2008). It is therefore important to investigate likely antecedents of students' motivation. Towards this end, SDT-based research has shown that students benefit more when they perceive the learning environment as autonomy-supportive (i.e. when teachers consider students' interests and perspective) and well-structured (i.e. when there are clear, consistent, and properly justified guidelines and rules) (Reeve, Jang, Carrell, Jeon, \& Barch, 2004; Soenens, Sierens, Vansteenkiste, Dochy, \& Goossens, 2012). 
Although it becomes apparent that the perceived learning environment predicts desired educational outcomes, partly because it enhances quality of motivation (Deci \& Ryan, 2000), there is no systematic evidence for the longitudinal sequence of these hypothesised relations in the middle and high school environment (for a few notable exceptions, see Jang, Kim, \& Reeve, 2012, 2016). This is an important issue to be addressed, because showing that perceived learning environment is associated with positive educational outcomes in the long run via a motivational pathway, will provide further evidence that facilitating students' autonomous motivation is a worthwhile investment that can yield not only short-term but also long-lasting benefits to the students. In addition, only few studies have concomitantly examined whether both perceived autonomy support and structure relate to autonomous and controlled motivation (e.g. Vansteenkiste et al., 2012) and whether these motivational subtypes predict in turn changes in study effort or procrastination.

Our aim in the present study was twofold. First, we aimed to test the theory-driven assumption that autonomous-supportive and well-structured contexts facilitate in the long term educational outcomes because they enhance autonomous motivation and keep at bay controlled motivation. Second, we sought to examine whether both perceived autonomy support and structure relate to desired educational outcomes. In that way, we aimed to highlight the key role that teachers can play to enhance students' quality of motivation and in turn their study effort. We aimed to pursue our two aims through a more demanding research design (i.e. a prospective study where we controlled for baseline levels of study effort) and rigorous statistical test (i.e. through path analysis and after controlling for classlevel shared variance).

\section{Autonomous and controlled motivation at school}

According to SDT (Deci \& Ryan, 2000; Ryan \& Deci, 2017), students may study because they consider the study material interesting, pleasant, and fascinating (intrinsic motivation), an integral part of their own system values and beliefs (integrated regulation), or personally valuable (identified regulation). As these reasons imply personal volition, they all reflect autonomous motivation. Students however may also study either to prove their self-worth, or to avoid feelings of guilt or shame (introjected regulation); they may also study, to get some tangible rewards, or avert punishments or disapproval from significant others (external regulation). These reasons are presumed to exert internal or external psychological pressure, respectively, and hence represent controlled forms of motivation.

Numerous studies have demonstrated that as compared to controlled motivation, autonomous motivation relates to adaptive outcomes (for review see Guay et al., 2008; Vansteenkiste, Niemiec, \& Soenens, 2010), such as the use of adaptive learning strategies (Soenens et al., 2012; Vansteenkiste, Sierens, Soenens, Luyckx, \& Lens, 2009) and persistence (Vansteenkiste, Simons, Lens, Sheldon, \& Deci, 2004). However, only few studies have examined whether autonomous and controlled motivation at the beginning of the school year predict learning-related outcomes at the end of the school year. To the best of our knowledge, the only research examining whether autonomous and controlled motivation predict educational correlates across time was conducted by Otis, Grouzet, and Pelletier (2005). Consistent with SDT, these authors showed that 9th-grade intrinsic motivation and identified regulation predicted positively homework engagement and negatively absenteeism and dropout intentions in the10th-grade. In contrast, 8th-grade external regulation (a component 
of controlled motivation) yielded an opposite pattern of associations with these outcomes in the10th-grade.

In the present prospective study, we aimed to complement the work of Otis et al. (2005) by showing that beginning-of-school-year quality of motivation does predict end-of-schoolyear self-reported study effort and procrastination, even after statistically controlling for beginning-of-school-year study effort and procrastination. Such a statistical control was undertaken by a more recent three-wave, one-semester longitudinal study with Korean middle school students (Jang et al., 2012). Although Jang et al. (2012) did not assess autonomous and controlled motivation but need satisfaction (which is considered a proxy of autonomous motivation), they found begin-of-semester perceived autonomy support to predict end-semester classroom engagement and grades by means of mid-semester autonomy need satisfaction. These associations were found after statistically controlling for baseline measures of each construct. We aimed to complement these findings by examining whether next to perceived autonomy support, perceived structure would also predict study effort and procrastination by means of autonomous and controlled motivation after controlling for begin-of-school year study effort and procrastination and the shared variance due to classroom membership.

\section{Autonomy support and structure in the classroom}

In autonomy-supportive classrooms teachers nurture students' inner motivational resources and attune learning activities to students' personal preferences, interests, and values (Reeve, 2006). For instance, autonomy-supportive teachers offer choices that are aligned with students' interests and goals and share some of their authority with their students by avoiding using directives and pressuring language such as 'should', 'oughts', and 'musts'. In addition, autonomy-supportive teachers show respect to their students by acknowledging their negative feelings (Deci, Eghrari, Patrick, \& Leone, 1994), and highlight the importance and relevance of the learning activities (Jang, 2008; Katz \& Assor, 2007).

Several cross-sectional (e.g. Ntoumanis, 2005; Tsai, Kunter, Lüdtke, \& Ryan, 2008), experimental (e.g. Reeve et al., 2004; Vansteenkiste, Simons, Lens, Soenens, \& Matos, 2005), and longitudinal studies (e.g. Reeve et al., 2004; Skinner, Furrer, Marchland, \& Kindermann, 2008) have indicated that perceived autonomy supportive classroom environment relate to positive educational outcomes, including autonomous motivation (Haerens, Aelterman, Vansteenkiste, Soenens, \& Van Petegem, 2015), conceptual learning (Reeve et al., 2004; Vansteenkiste et al., 2005), learning effort (León, Núñez, \& Liew, 2015), task involvement, and performance (Patall, Cooper, \& Wynn, 2010; for a recent review see Stroet, Opdenakker, \& Minnaert, 2013).

SDT maintains however that classrooms need to be not only autonomy supportive but also well-structured (Skinner, Zimmer-Gembeck, \& Connell, 1998). Teachers who provide structure render the classroom environment more predictable for their students. They do so by setting clear rules and expectations, offering rationales for these rules, and behaving in a consistent way. In that way teachers provide a'roadmap' about how students can proceed to attain their goals. In addition, teachers who provide structure help and support their students by adjusting their teaching pace according to their students' progress (Reeve, 2006; Skinner et al., 1998), so that students can gradually develop their skills (Jang, Reeve, \& Deci, 2010; Vansteenkiste et al., 2012). Several studies indicated that perceived structure is 
positively associated with autonomous motivation (Taylor \& Ntoumanis, 2007), behavioural engagement (for a review see Stroet et al., 2013), and the use of effective learning strategies (Sierens, Vansteenkiste, Goossens, Soenens, \& Dochy, 2009), while a recent four-wave observational study indicated that teacher structure positively related to student-reported autonomous motivation (Stroet, Opdenakker, \& Minnaert, 2015).

As this brief overview suggests, autonomy support and structure are both conducive of positive educational outcomes. Indeed, a few studies that measured both perceived structure and autonomy support showed that they both predict positive educational outcomes, such as autonomous motivation, effective learning strategies (Vansteenkiste et al., 2012), and collective engagement (Jang et al., 2010). Although, in most of these studies it is either implicitly or explicitly argued that perceived autonomy support and structure facilitates educational outcomes because it enhances autonomous motivation, this assumption has remained largely untested.

In addition, SDT suggests that autonomy support and structure can work in tandem but may also be more disconnected from one another. Although perceived structure and autonomy support are on average positively correlated (e.g. Sierens et al., 2009), some teacher may provide autonomy support but no structure and vice versa. A few studies have shown that the simultaneous presence of autonomy support and structure comes with extra benefits (e.g. Curran, Hill, \& Niemiec, 2013; Sierens et al., 2009) but others could not confirm such a pattern of findings (e.g. Jang et al., 2010). Therefore, it remains unclear if perceived autonomy support and structure relate in a synergistic fashion with motivational process and outcomes.

\section{The present research}

In this study, we aimed to investigate through a process model to what extent beginningof-school year perceived autonomy support and structure relate to autonomous and controlled motivation and whether in turn autonomous and control motivation predict end-of-school year study effort and procrastination. In doing so, we controlled for initial levels of study effort and procrastination and we partialed out the shared variance due to classroom membership. Testing such a process model would help us discern to what degree perceived autonomy support, structure, (and perhaps their interaction) predict students' outcomes through different mediational mechanisms - for instance, whether perceived autonomy support positively predicts study effort through autonomous motivation or negatively predicts procrastination via controlled motivation.

We selected students' study effort (herein defined as students' propensity to effectively regulate their study effort and attention in the face of distractions) as a marker of adaptive learning practices because study effort has been found to relate to subsequent achievement (Credé \& Phillips, 2011). Therefore, study effort represents one's attempts to control studying to do well at school (Pintrich, 2004). Prior research has provided evidence for the positive link between autonomous functioning and study effort (e.g. Liu et al., 2014; Mouratidis, Michou, \& Vassiou, 2017) as autonomous motivation is more likely to propel students to exert effort in their studies even in the face of difficulties (León et al., 2015).

Likewise, we opted for procrastination (defined as students' propensity to delay activities that need to be accomplished within a given frame of time) as a maladaptive indicator, given its prevalence among students, and its links with ineffective learning, underachievement 
and ill-being (Steel, 2007). Previous empirical studies have indicated that procrastination is associated negatively with autonomous motivation (Burnam, Komarraju, Hamel, \& Nadler, 2014; Senécal, Julien, \& Guay, 2003). Presumably, autonomously motivated students are more likely to initiate their academic activities on time as for them these activities are more joyful or personally important and thus less aversive - a factor that has consistently linked with procrastination (see Steel, 2007). In contrast, students who feel psychological pressure to do their schoolwork may consider academic tasks as more aversive, and may temporarily rebel against engaging in these task, or may only carry them out when no further postponement is possible.

We tested three hypotheses (see Figure 1) and one research question. First, given that autonomy-supportive (Deci \& Ryan, 2000) and properly-structured (Skinner et al., 1998) contexts are more likely to foster autonomous motivation, we hypothesised that both perceived autonomy support and structure would predict positively autonomous motivation (Hypothesis 1a) and negatively or not predict at all controlled motivation (Hypothesis 1b). Second, in line with previous research (Vansteenkiste et al., 2004), we expected autonomous motivation to predict end-of-school year increases in study effort and decreases in procrastination (Hypothesis 2a). This is because students who enjoy or personally value schoolwork (and not consider it as an obligation) are more likely to better and better regulate their study effort and to procrastinate less. As for controlled motivation, we expected, similar to prior studies (e.g. Burnam et al., 2014; Katz, Eilot, \& Nevo, 2014), that it would positively predict end-of-school year procrastination (Hypothesis 2b). On the other hand, such a negative relation was not necessarily expected for study effort (see Aelterman et al., 2012). This is because students who are under psychological pressure to do their schoolwork may either make little effort to do their homework to react to that pressure (so a negative relation is expected in that case), or feel accountable for doing their homework because of that pressure (so a positive relation is expected in that case).

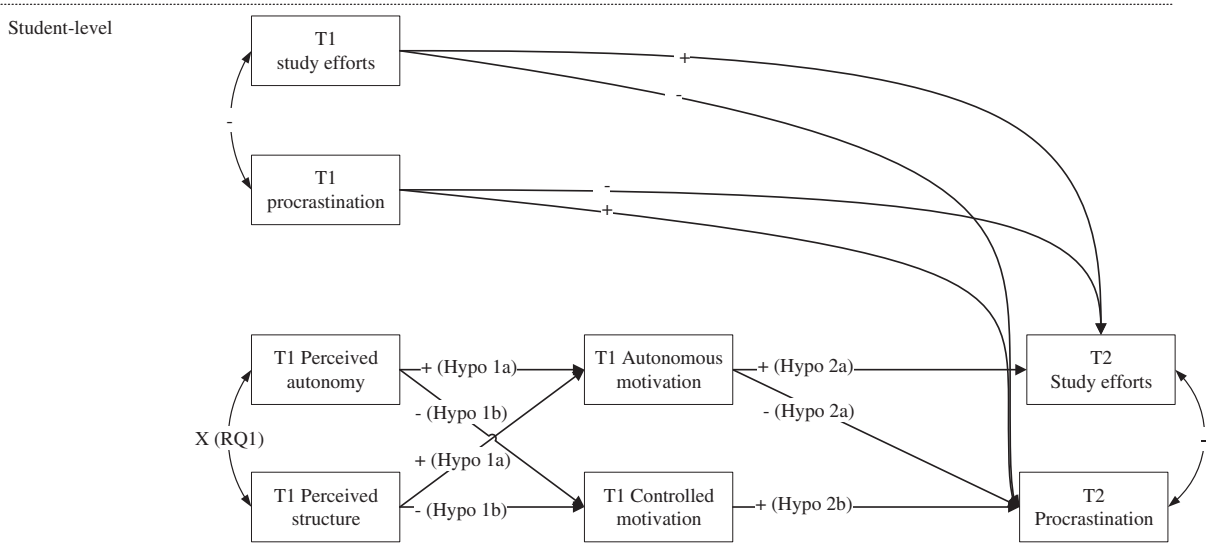

Figure 1. The hypothesised multilevel path model. 
Third, aligned with one of the fundamental assumptions of SDT (Deci \& Ryan, 2000) and the scant empirical evidence (e.g. Ntoumanis, 2005), we anticipated that autonomous and controlled motivation would, at least partly, mediate the relation of perceived autonomy support and structure to study effort and procrastination (Hypothesis 3). Finally, given the inconsistent findings in the literature (e.g. Curran et al., 2013; Jang et al., 2010; Sierens et al., 2009), we explored, in supplementary analyses, whether perceived autonomy support and structure would interact in the prediction of the learning outcomes.

\section{Method}

\section{Participants and procedure}

An approval to conduct the study was granted by the ethical board of the host University. Data were collected in two waves, at the beginning and the end of the school year ( $\mathrm{T} 1$, October-November; T2, May). Participants at T1 were $886(N=885$ at T2) middle and high school students $(32.7 \%$ males) and were attending the 7 th $(N=237 ; 26.7 \%), 8$ th $(N=253$; $28.6 \%)$, 9th $(N=110 ; 12.4 \%), 10$ th $(N=112 ; 12.6 \%), 11$ th $(N=100 ; 11.3 \%)$, or 12 th $(N=74$; $8.4 \%$ ) grade. Students were nested into 49 different classes (Mean class size $=18.08$ students, $\mathrm{SD}=4.83)$, nested into two general education schools located in a region of average socioeconomic status in Flanders, Belgium. Most students (approximately 90\%) held Belgian nationality and belonged to the Flemish community. In Flanders, compulsory education is between the ages of 6 and 18. Secondary education consists of six years starting from the age of 12 and has four types of educational track (general, technical, vocational, and art education).

In both waves, a research assistant visited the schools and, during a class hour, briefly described to the students the scope of the study. After being informed that their participation was voluntary and that their responses would remain confidential, students filled out the questionnaires in their classrooms during regular class hours. Students answered to questions referring to perceived autonomy support and structure and their autonomous and controlled motivation at $\mathrm{T} 1$, while at both $\mathrm{T} 1$ and $\mathrm{T} 2$ they answered to questions pertinent to their study effort and procrastination. All the questionnaires were presented in a five-point Likert-type format, with anchors ranging from 1 (strongly disagree) to 5 (strongly agree).

\section{Measures}

\section{T1 perceived autonomy support}

The relevant subscale from the Teacher as Social Context questionnaire (TASCQ; Belmont, Skinner, Wellborn, \& Connell, 1988) was employed to assess the degree to which students perceived that their teachers were autonomy-supportive. Students were asked to rate to what degree they believed that their teachers provided choice (two items; e.g. 'My teachers let me choose how I approach my schoolwork'), took their perspective (two items; e.g. 'My teachers listen to my ideas'), and highlighted the usefulness and relevance of learning activities (two items; e.g. 'My teachers talk about how I can use the things we learn in school'). A Confirmatory Factor Analysis (CFA) for a three-factor model where the three pairs of items assessing choice, perspective-taking, and relevance defined the respective latent factors (after imposing equality constraints on each pair), which in turn defined a higher-order factor 
(i.e. perceived autonomy support) yielded the following fit: $S-B X^{2}(9, N=860)=18.91, p=.026$, $\mathrm{CFI}=.988, \mathrm{SRMR}=.019$, RMSEA $=.036(90 \%-\mathrm{Cl}: .014-.057)$. A composite score of perceived autonomy support for each student was created by aggregating the six items (Cronbach alpha $=.68)$.

\section{T1 perceived structure}

Students' perceptions of teacher structure were assessed by means of a shortened version of the respective subscale of TASCQ (Belmont et al., 1988). Students indicated to what extent their class teachers exhibited contingent behaviour (e.g.' 'Every time I do something wrong, my teachers act differently' reverse scored), set clear expectations (e.g. 'My teachers make clear what they expect of me in school'), provided help and support (e.g.'My teachers show me how to solve problems for myself'), and adjusted and monitored their teaching accordingly (e.g. 'My teachers check to see if I'm ready before they start a new topic'). Two items were used for each subscale and the CFA for a model where each pair of items (with equality constraints being imposed on each pair) loaded on the respective latent factor (i.e. contingency, expectations, help and support, and adjustment and monitoring), which then loaded on a higher-order latent factor, termed perceived structure was acceptable $S-B X^{2}(20$, $N=853)=53.66, p<.01, \mathrm{CFI}=.970, \mathrm{SRMR}=.047, \mathrm{RMSEA}=.044$ (90\%-Cl: .030-.059). A composite score of perceived structure was computed for each student by averaging the eight items (Cronbach alpha $=.66)$.

\section{T1 autonomous and controlled motivation}

We adapted sixteen items from Ryan and Connell's Self-Regulated Questionnaire (1989) to assess the extent to which students consider their daily schoolwork (see Vansteenkiste et al., 2009) as (a) autonomously motivated - that is, as intrinsically satisfying (4 items; e.g. 'I study because I want to learn new things'; $a=.90$ ) or valuable and important (i.e. identified regulation; 4 items; e.g.'I study because this is for me an important personal choice'; $a=.80$ ), or (b) psychologically pressuring due to forces that are internal (i.e. introjected regulation; 4 items; e.g. 'I study because I want to give others the impression that I am a good student'), or external (i.e. external regulation; 4 items; e.g. 'I study because others force me to do so'). A CFA in which an intrinsic item cross loaded on both the intrinsic and identified latent factors, and two external regulation items cross loaded on both the introjected and external latent factors yielded marginally accepted fit $S-B X^{2}(19, N=877)=605.44, p<.01, C F I=.914$, $\mathrm{SRMR}=.055, \mathrm{RMSEA}=.079$ (90\%-Cl: .073-.084). Autonomous motivation score was calculated by averaging the items assessing intrinsic motivation and identified regulation, while controlled motivation score was calculated by aggregating the introjected and external regulation items. The internal consistency (Cronbach alphas) for the autonomous and controlled motivation subscales was .89 and .72 , respectively.

\section{T1 and T2 study effort and procrastination}

We used the subscale of effort regulation from the Motivated Strategies for Learning Questionnaire (MSLQ; Pintrich, Smith, Garcia, \& McKeachie, 1991) to assess to what extent students believed that they effectively regulated study effort at school (4 items; e.g. 'Even when course materials are dull and uninteresting, I manage to keep working until I finish'; $\mathrm{T} 1 a=.79 ; \mathrm{T} 2 a=.77)$. 
To assess students' procrastination, we used ten items from the Lay's General Procrastination Scale (1986). The scale had been previously translated into Dutch and adapted to the educational context by Depreeuw and Lens (1998; see also Dewitte \& Schouwenburg, 2002; Schouwenburg, 1992). Students were asked to what extent they tend to postpone their studying and/ or replaced their homework with less important - yet, more pleasant - activities. An example item reads, 'I start studying later than I had intended to', and the Cronbach alpha of the procrastination scale was .90 both at T1 and T2.

A CFA with a two-latent-factor model (one for study effort and another one for procrastination) yielded acceptable fit for $T 1: S-B X^{2}(76, N=873)=295.23, p<.01, C F I=.954$, SRMR $=.041, \mathrm{RMSEA}=.058(90 \%-C l: .051-.064)$, and the same was true for T2: $S-B X^{2}(76$, $N=860)=249.52, p<.01, \mathrm{CFI}=.962, \mathrm{SRMR}=.040, \mathrm{RMSEA}=.052(90 \%-C l: .044-.059)$. A test of time invariance with equality constraints imposed on the item loadings and the factor covariances across the two measurement waves (i.e. test of weak invariance) showed reasonable fit: $S-B X^{2}(165)=568.46, p<.01, C F I=.957$, SRMR $=.045, \operatorname{RMSEA}=.053(90 \%-C l$ : $.048-.058)$, suggesting that the two scales worked in a similar way in both waves.

\section{Results}

\section{Preliminary analyses}

Descriptive statistics and bivariate correlations among the measured variables of the study are displayed in Table 1. Preliminary analyses revealed statistically significant gender differences in the means of the linear combination of the measured variables, Wilk's $\lambda=.956, F(8$, $830)=4.73 p<.01$, multivariate $\eta^{2}=.04$. Therefore, gender was included as a covariate in the main analyses.

\section{Primary analyses}

To test our hypotheses, we set up a multilevel model, given the nested structure of the data (students nested within classrooms). In that model, T1 perceived autonomy support and structure were used as group-mean centred predictors of 2 study effort and procrastination, with $\mathrm{T} 1$ autonomous and controlled motivation mediating these associations. Gender, as well as T1 study effort and procrastination were also included as covariates. Although including aggregating scores of autonomy and structure as class-level predictors was technically feasible, we avoided including them for conceptual reasons because students might bear in mind different teachers when they responded to the questions that refer to perceived autonomy support and structure.

The hypothesised model, shown in Figure 2, yielded an acceptable fit: $\left(x^{2}[8]=36.11\right.$, $p<.01, \mathrm{CFI}=.986, \mathrm{TLI}=.937, \mathrm{SRMR}=.012, \mathrm{RMSEA}=.063)$. In line with Hypothesis $1 \mathrm{a}, \mathrm{T} 1$ perceived autonomy support and structure were both positively related to T1 autonomous motivation. Hypothesis 1b was partially supported as T1 perceived structure (but not perceived autonomy support) was negatively related to T1 controlled motivation. Furthermore, consistent to Hypothesis $2 \mathrm{a}$, we found $\mathrm{T} 1$ autonomous motivation to predict positively $\mathrm{T} 2$ study effort and negatively procrastination, after controlling for their T1 levels. In contrast, T1 controlled motivation positively predicted $\mathrm{T} 2$ procrastination but not study effort, providing thus support to Hypothesis $2 b$. 


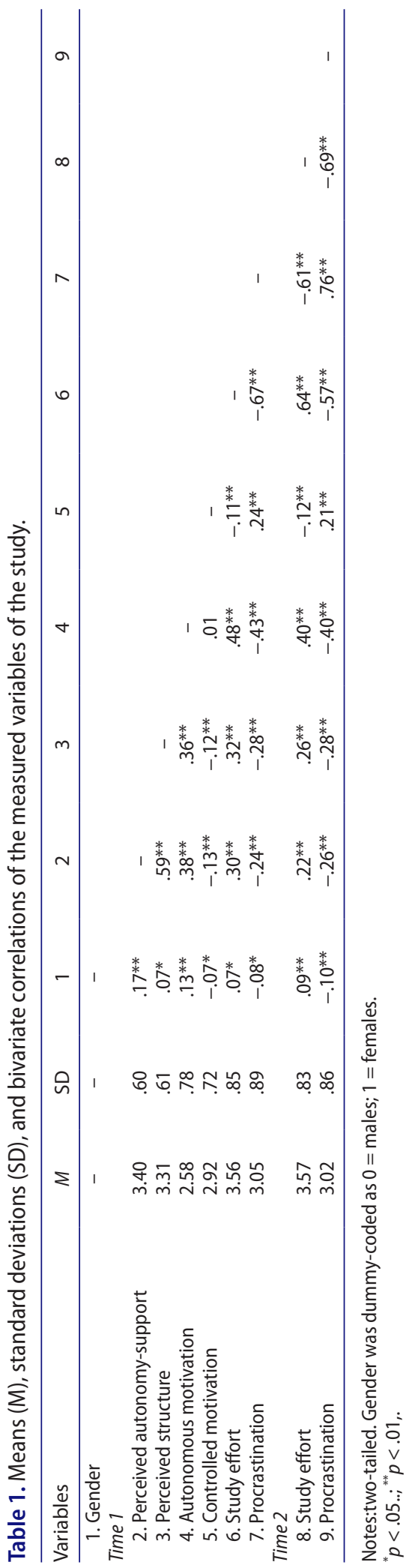




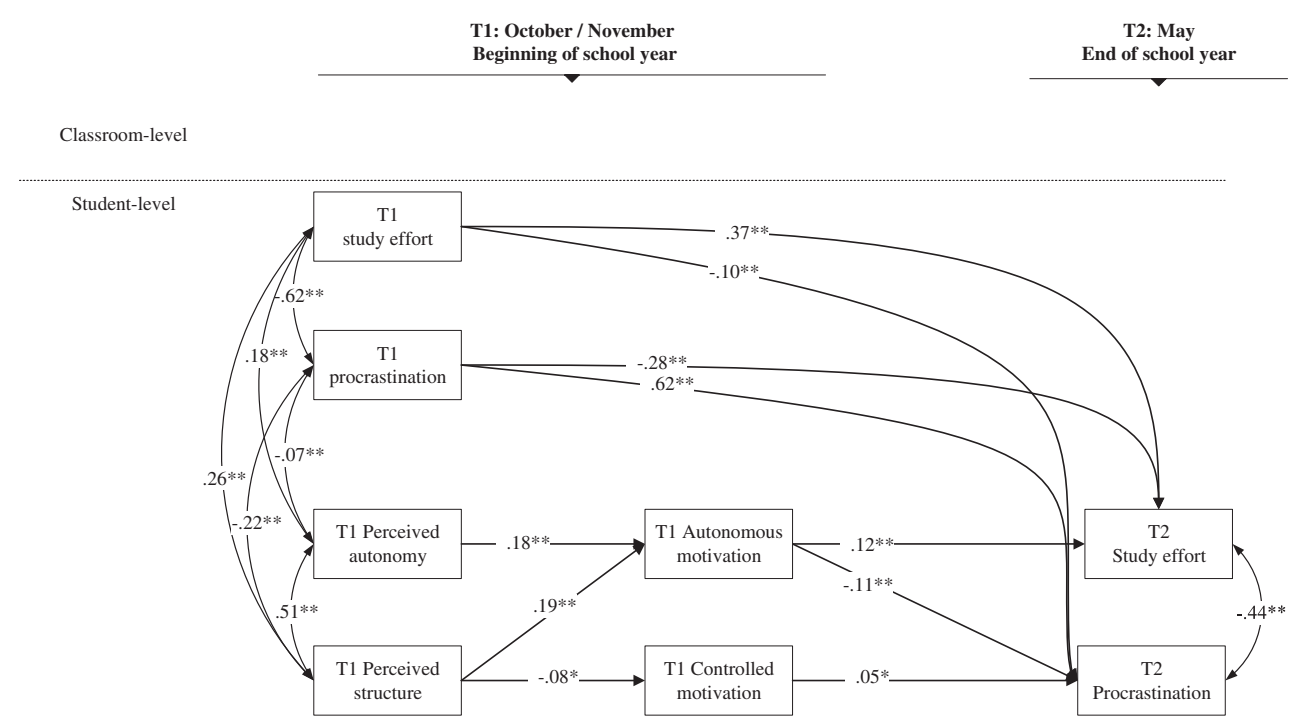

Figure 2. The tested multilevel path model, controlling for gender (not Shown for reasons of parsimony; for the same reasons are not shown the paths Linking $\mathrm{T} 1$ study effort and procrastination with $\mathrm{T} 1$ autonomous and controlled motivation).

Notes: All Path Coefficients Are Standardised. ${ }^{*} p<.05{ }^{* * *} p<.01$, two-tailed.

A test of indirect effects showed that T1 perceived autonomy support and structure were indirectly related to T2 study effort (respectively, $B=.03, \mathrm{SE}=.01, z=3.53, p<.01, \beta=.02$ and $B=.03, \mathrm{SE}=.01, z=3.05, p<.01, \beta=.02$ ) and procrastination (respectively, $B=-.03$, $\mathrm{SE}=.01, z=-3.20, p<.01, \beta=-.02$ and $B=-.03, \mathrm{SE}=.01, z=-3.63, p<.01, \beta=-.02$ ) through autonomous motivation. In contrast, the indirect path between T1 perceived structure and T2 procrastination by means of controlled motivation was statistically nonsignificant $(B=-.01, \mathrm{SE}=.03, z=-1.57, p=.12, \beta=.00)$. Taken together, these findings suggest that autonomous (but not controlled) motivation mediated the relations of perceived autonomy support and structure to study effort and procrastination. This finding provided partial support to Hypothesis 3. Regarding gender differences (not shown in Figure 2), these were statistically significant in the prediction of autonomous motivation $(\beta=.12, p<.01)$. Given the coding scheme $(0=$ males; $1=$ females $)$, this finding suggests that females reported higher levels of autonomous motivation than males.

\section{Supplementary analyses}

Finally, to address the supplementary research question of interaction between perceived autonomy support and structure, we tested in four separate hierarchical regression models whether perceived autonomy support and structure (after being centred around their means) and their interaction would predict autonomous motivation, controlled motivation, study effort, or procrastination. In none of the models the interaction was statistically significant. 


\section{Discussion}

Students who better regulate their study effort and avoid procrastination when doing their schoolwork are more likely to progress and achieve academically (Credé \& Phillips, 2011; Pintrich \& De Groot, 1990; Steel, 2007). Therefore, it is important to better understand why some students may better regulate their learning efforts than others. In our prospective study, we found that students' perceptions of whether their classroom is autonomy-supportive and properly structured in the very first weeks of a school year predicted, through autonomous motivation, longitudinal changes in study effort and procrastination by the end of the school year. Having controlled for the shared variance due to classroom membership and initial level of study effort and procrastination, we tested three interrelated hypotheses and provided some evidence that perceived autonomy support and structure in the classroom and autonomous motivation relate to aspects of self-reported learning processes and practices. The discussion revolves around these three hypotheses.

Like previous studies (e.g. Alivernini \& Lucidi, 2011; Lavigne \& Vallerand, 2010), which showed perceived autonomy support to relate to desired correlates because it enhances autonomous motivation (Deci \& Ryan, 2000; Guay et al., 2008), we found that perceived autonomy support related positively to autonomous motivation which, in turn, predicted study effort and procrastination at the end of the school year. We found the same pattern of relations for perceived structure, which in addition related negatively to controlled motivation.

But why perceived autonomy support did not relate negatively to controlled motivation once perceived structure was considered? Does this imply that structure might be more effective than autonomy support (as it related not only positively to autonomous motivation, but also negatively to controlled motivation)? Prior research has shown that both autonomy support and structure are conducive to positive outcomes (Jang et al., 2010; Sierens et al., 2009), but their relation to unwanted processes (such as controlled motivation) and maladaptive outcomes (such as procrastination) is less investigated. For instance, when teachers behaviours had been assessed through external observers (rather than through students' perceptions), Stroet et al. (2015) found only structure (and not autonomy support) to covary positively with student-reported autonomous motivation and negatively to amotivation. Future research needs to address this issue. Until then, the present findings underscore the importance of perceived autonomy support and structure as they both yielded unique relations to autonomous motivation.

Consistent with the second hypothesis, autonomous motivation predicted increased endof-school year study effort and decreased procrastination. These results suggest that students who find schoolwork interesting and valuable are more likely to study even harder and procrastinate even less in the long run. Conversely, students who feel psychologically pressured to study tend to procrastinate more over time.

Aligned with the third hypothesis, autonomous motivation (but not controlled one) appeared to mediate the relations of perceived autonomy support and structure to study effort and procrastination. Although these findings come as no surprise (see Otis et al., 2005; Soenens et al., 2012), they increase our confidence that this is the case for three reasons. First, in our study we tried to reduce the method bias that may inflate these associations as we controlled for the shared variance due to classroom membership; second, we controlled for beginning-of-school year study effort and procrastination; and third, end-of-school year 
study effort and procrastination were assessed six months apart from the assessment of autonomous and controlled motivation. It seems thus that autonomous motivation indeed acts as a mediating mechanism that can explain the relation of perceived autonomy support and structure to desired educational outcomes. Further, given that autonomous motivation was related positively to T1 study effort and negatively to T1 procrastination (see Table 1), our findings tempt us to suggest that a virtuous circle may also operate: That is, once a teacher is perceived to provide autonomy support and structure, this is likely to enhance students' autonomous motivation which in turn may lead students put more effort in their everyday studying, a behaviour which will be experienced as self-rewarding that will further fuel their autonomous motivation which in turn is more likely to further boost their study effort in the long run. (see Jang et al., 2016 for such a recursive model). Through a similar process, it is likely that students who are more autonomously motivated may encourage their teachers become even more autonomous supportive (Pelletier \& Vallerand, 1996), so that a positive spiral between students' quality of motivation and teachers' instructional style is likely to emerge as well.

Contrary to a few previous studies (e.g. Sierens et al., 2009), but in line with some others (e.g. Jang et al., 2010), we found no interaction between perceived autonomy support and structure. Is this because perceived autonomy support and structure may synergistically predict certain outcomes such as positive and negative emotions but not others such as behavioural engagement as a recent study has shown (Hospel \& Galand, 2016)? Future research needs to address this issue.

The present results also revealed that females were more autonomous motivated than males. Similar gender differences have been occasionally reported in the literature (e.g. Vallerand \& Bissonnette, 1992) and may capitalise on chance or could perhaps be due to females' special interest in school-related tasks (Xu, 2008).

\section{Limitations}

The study has some limitations that should be acknowledged. First, there is a potential threat for monomethod bias as the results are based on students' self-reports and not on actual behaviour. Given the inconsistencies that sometimes lie between self-reported and actual behaviour (Baumeister, Vohs, \& Funder, 2007), future research will need to triangulate students' reports with unobtrusive observations and (or) by teachers' ratings (Haerens et al., 2013). Second, the coefficients of the paths linking perceived structure with controlled motivation and controlled motivation with procrastination were small in magnitude and their statistical significance could be owed to the relatively large statistical power. Third, caution is warranted when generalising these findings to other populations who differ in age and cultural background, although similar links have been observed across different population samples, contexts, or cultures (e.g. Alivernini \& Lucidi, 2011; Chirkov \& Ryan, 2001; Hagger, Chatzisarantis, Barkoukis, Wang, \& Baranowski, 2005; Levesque, Zuehlke, Stanek, \& Ryan, 2004). Also, study effort is dynamic in nature; hence future studies will need to use complementary measures such as diary methods, and think-aloud protocols. Moreover, we overlooked students' perceptions about whether the classroom is relatedness supportive through teachers' involvement (Skinner et al., 1998). In addition, autonomy and structure as class-level predictors were not tested given that the questions addressing students' perceptions were not focused on a particular class. Therefore, students from different classes could have similar 
teachers in mind, or, students from the same class may focused on different classes or subject matters while answering to the questionnaires. More important, no causality can be inferred, as only studies with experimental designs could establish causal links.

\section{Conclusion and future research directions}

The more students perceive the learning environment of their classroom as autonomy supportive and well-structured, the more they report that they are autonomously motivated; and the more they do so the more they report that they use effective learning strategies in the long run. In practice, this means that if teachers want their students to become more autonomously motivated and use more effective learning strategies and practices they may want to empathise with their students, take their perspective and, concomitantly, set clear rules, behave in a consistent way and provide tailored help and guidance to them.

Future research may need to use multiple methods to assess or to experimentally manipulate the learning environment across the dimensions of autonomy support and structure to test whether each of them is specialised to certain outcomes - for instance, whether objectively assessed autonomy support enhances autonomous motivation and well-being while structure facilitates objectively assessed (rather than self-reported) learning processes and practices. Future research needs to include also diary (e.g. Patall, Vasquez, Steingut, Trimble, \& Pituch, 2016; van der Kaap-Deeder, Vansteenkiste, Soenens, \& Mabbe, 2017) studies that will assess at a more micro-analytic level the ongoing dynamics between need-supportive contexts and well-adjustment. This will enable researchers to understand how autonomy support and structure evolves across time and how each of them covaries with day-to-day or week-to-week teachers' instructional practices and students' cognitive, affective, and behavioural responses.

\section{Disclosure statement}

No potential conflict of interest was reported by the authors.

\section{ORCID}

A. Mouratidis (D) http://orcid.org/0000-0003-0325-8077

\section{References}

Aelterman, N., Vansteenkiste, M., Van Keer, H., Van den Berghe, L., De Meyer, J., \& Haerens, L. (2012). Students' objectively measured physical activity levels and engagement as a function of betweenclass and between-student differences in motivation toward physical education. Journal of Sport \& Exercise Psychology, 34, 457-480.

Alivernini, F., \& Lucidi, F. (2011). Relationship between social context, self-efficacy, motivation, academic achievement, and intention to drop out of high school: A longitudinal study. The Journal of Educational Research, 104, 241-252. doi:10.1080/00220671003728062

Baumeister, R. F., Vohs, K. D., \& Funder, D. C (2007). Psychology as the science of self-reports and finger movements. Perspectives on Psychological Science, 2, 396-403.

Belmont, M., Skinner, E., Wellborn, J., \& Connell, J. (1988). Teacher as social context. A measure of student perceptions of teacher provision of involvement, structure, and autonomy support (Tech. Rep. No. 102). Rochester, NY: University of Rochester. 
Burnam, A., Komarraju, M., Hamel, R., \& Nadler, D. R. (2014). Do adaptive perfectionism and selfdetermined motivation reduce academic procrastination? Learning and Individual Differences, 36, 165-172. doi:10.1016/j.lindif.2014.10.009

Chirkov, V. I., \& Ryan, R. M. (2001). Parent and teacher autonomy-support in Russian and U.S. adolescents: Common effects on well-being and academic motivation. Journal of Cross-Cultural Psychology, 32, 618-635. doi:10.1177/0022022101032005006

Credé, M., \& Phillips, L. A. (2011). A meta-analytic review of the motivated strategies for learning questionnaire. Learning and Individual Differences, 21, 337-346. doi:10.1016/j.lindif.2011.03.002

Curran, T., Hill, A. P., \& Niemiec, C. P. (2013). A conditional process model of children's behavioral engagement and behavioral disaffection in sport based on self-determination theory. Journal of Sport \& Exercise Psychology, 35, 30-43.

Deci, E. L., \& Ryan, R. M. (2000). The "what" and "why" of goal pursuits: Human needs and the self determination of behavior. Psychological Inquiry, 11, 227-268. doi:10.1207/S15327965PLI1104_01

Deci, E. L., Eghrari, H., Patrick, B. C., \& Leone, D. R. (1994). Facilitating internalization:The self-determination theory perspective. Journal of Personality, 62, 119-142. doi:10.1111/j.1467-6494.1994.tb00797.x

Depreeuw, E., \& Lens, W. (1998). Vragenlijst aangaande Studie-Organisatie-Vaardigheden-VaSOV [Study management skills: A questionnaire]. Unpublished manuscript, Center for Research in Motivation and Time Perspective, Catholic University Leuven, Belgium.

Dewitte, S., \& Schouwenburg, H. C. (2002). Procrastination, temptations, and incentives: The struggle between the present and the future in procrastinators and the punctual. European Journal of Personality, 16, 469-489.

Guay, F., Ratelle, C. F., \& Chanal, J. (2008). Optimal learning in optimal contexts: The role of selfdetermination in education. Canadian Psychology, 49, 233-240. doi:10.1037/a0012758

Haerens, L., Aelterman, N., Van den Berghe, L., De Meyer, J., Soenens, B., \& Vansteenkiste, M. (2013). Observing physical education teachers' need-supportive interactions in classroom settings. Journal of Sport \& Exercise Psychology, 35, 3-17.

Haerens, L., Aelterman, N., Vansteenkiste, M., Soenens, B., \& Van Petegem, S. (2015). Do perceived autonomy-supportive and controlling teaching relate to physical education students' motivational experiences through unique pathways? Distinguishing between the bright and dark side of motivation. Psychology of Sport and Exercise, 16, 26-36. doi:10.1016/j.psychsport.2014.08.013

Hagger, M. S., Chatzisarantis, N. L. D., Barkoukis, V., Wang, C. K. J., \& Baranowski, J. (2005). Perceived autonomy support in physical education and leisure-time physical activity: A cross-cultural evaluation of the trans-contextual model. Journal of Educational Psychology, 97, 376-390. doi:10.1037/00220663.97.3.376

Hospel, V., \& Galand, B. (2016). Are both classroom autonomy support and structure equally important for students' engagement? A multilevel analysis. Learning and Instruction, 41, 1-10. doi:10.1016/j. learninstruc.2015.09.001

Jang, H. (2008). Supporting students' motivation, engagement, and learning during an uninteresting activity. Journal of Educational Psychology, 100, 798-811. doi:10.1037/a0012841

Jang, H., Reeve, J., \& Deci, E. L. (2010). Engaging students in learning activities: It's not autonomy support or structure, but autonomy support and structure. Journal of Educational Psychology, 102, 588-600. doi:10.1037/a0019682

Jang, H., Kim, E. J., \& Reeve, J. (2012). Longitudinal test of self-determination theory's motivation mediation model in a naturally occurring classroom context. Journal of Educational Psychology, 104, 1175-1188. doi:10.1037/a0028089

Jang, H., Kim, E. J., \& Reeve, J. (2016). Why students become more engaged or more disengaged during the semester: A self-determination theory dual-process model. Learning and Instruction, 43, 27-38. doi:10.1016/j.learninstruc.2016.01.002

van der Kaap-Deeder, J., Vansteenkiste, M., Soenens, B., \& Mabbe, E. (2017). Children's daily wellbeing: The role of mothers', teachers', and siblings' autonomy support and psychological control. Developmental Psychology, 53, 237-251. doi:10.1037/dev0000218

Katz, I., \& Assor, A. (2007). When choice motivates and when it does not. Educational Psychology Review, 19, 429-442. doi:10.1007/s10648-006-9027-y 
Katz, l., Eilot, K., \& Nevo, N. (2014). "I'll do it later": Type of motivation, self-efficacy and homework procrastination. Motivation and Emotion, 38, 111-119. doi:10.1007/s11031-013-9366-1

Lavigne, G. L., \& Vallerand, R. J. (2010). The dynamic processes of influence between contextual and situational motivation: A test of the hierarchical model in a science education setting. Journal of Applied Social Psychology, 40, 2343-2359.

Lay, C. H. (1986). At last, my research article on procrastination. Journal of Research in Personality, 20, 474-495. doi:10.1016/0092-6566(86)90127-3

León, J., Núñez, J. L., \& Liew, J. (2015). Self-determination and STEM education: Effects of autonomy, motivation, and self-regulated learning on high school math achievement. Learning and Individual Differences, 43, 156-163. doi:10.1016/j.lindif.2015.08.017

Levesque, C., Zuehlke, A. N., Stanek, L. R., \& Ryan, R. M. (2004). Autonomy and competence in German and American university students: A comparative study based on self-determination theory. Journal of Educational Psychology, 96, 68-84. doi:10.1037/0022-0663.96.1.68

Liu, W. C., Wang, C. K. J., Kee, Y. H., Koh, C., Lim, B. S. C., \& Chua, L. L. (2014). College students' motivation and learning strategies profiles and academic achievement: A self-determination theory approach. Educational Psychology, 34, 338-353. doi:10.1080/01443410.2013.785067

Mouratidis, A., Michou, A., \& Vassiou, A. (2017). Adolescents' autonomous functioning and implicit theories of ability as predictors of their school achievement and week-to-week study regulation and well-being. Contemporary Educational Psychology, 48, 56-66. doi:10.1016/j.cedpsych.2016.09.001

Ntoumanis, N. (2005). A prospective study of participation in optional school physical education using a self-determination theory framework. Journal of Educational Psychology, 97, 444-453. doi:10.1037/0022-0663.97.3.444

Otis, N., Grouzet, F. M. E., \& Pelletier, L. C. (2005). Latent motivational change in an academic setting: A 3-year longitudinal study. Journal of Educational Psychology, 97, 170-183. doi:10.1037/00220663.97.2.170

Patall, E. A., Cooper, H., \&Wynn, S. R. (2010). The effectiveness and relative importance of choice in the classroom. Journal of Educational Psychology, 102, 896-915. doi:10.1037/a0019545

Patall, E. A., Vasquez, A. C., Steingut, R. R., Trimble, S. S., \& Pituch, K. A. (2016). Daily interest, engagement, and autonomy support in the high school science classroom. Contemporary Educational Psychology, 46, 180-194. doi:10.1016/j.cedpsych.2016.06.002

Pelletier, L. G., \& Vallerand, R. J. (1996). Supervisors' beliefs and subordinates' intrinsic motivation: A behavioral confirmation analysis. Journal of Personality and Social Psychology, 71, 331-340. doi:10.1037/0022-3514.71.2.331

Pintrich, P. R. (2004). A conceptual framework for assessing motivation and self-regulated learning in college students. Educational Psychology Review, 16, 385-407. doi:10.1007/s10648-004-0006-x

Pintrich, P. R., \& De Groot, E. V. (1990). Motivational and self-regulated learning components of classroom academic performance. Journal of Educational Psychology, 82, 33-40. doi:10.1037/0022-0663.82.1.33

Pintrich, P. R., Smith, D., Garcia, T., \& McKeachie, W. J. (1991). A manual for the use of the motivated strategies for learning questionnaire (MSLQ). Ann Arbor, MI: National Center for Research to Improve Postsecondary Teaching and Learning, University of Michigan.

Reeve, J. (2006). Teachers as facilitators: What autonomy-supportive teachers do and why their students benefit. The Elementary School Journal, 106, 225-236. doi:10.1086/501484

Reeve, J., Jang, H., Carrell, D., Jeon, S., \& Barch, J. (2004). Enhancing students' engagement by increasing teachers' autonomy support. Motivation and Emotion, 28, 147-169. doi:0146-7239/04/0600-0147/0

Ryan, R. M., \& Connell, J. P. (1989). Perceived locus of causality and internalization: Examining reasons for acting in two domains. Journal of Personality and Social Psychology, 57, 749-761. doi:10.1037/00223514.57.5.749

Ryan, R. M., \& Deci, E. L. (2017). Self-determination theory: Basic psychological needs in motivation, development, and wellness. New York, NY: Guilford Press.

Schouwenburg, H. C. (1992). Procrastinators and fear of failure: An exploration of reasons for procrastination. European Journal of Personality, 6, 225-236.

Senécal, C., Julien, E., \& Guay, F. (2003). Role conflict and academic procrastination: A self-determination perspective. European Journal of Social Psychology, 33, 135-145. doi:10.1002/ejsp.144 
Sierens, E., Vansteenkiste, M., Goossens, L., Soenens, B., \& Dochy, F. (2009). The synergistic relationship of perceived autonomy support and structure in the prediction of self-regulated learning. British Journal of Educational Psychology, 79, 57-68. doi:10.1348/000709908X304398

Skinner, E. A., Zimmer-Gembeck, M. J., \& Connell, J. P. (1998). Individual differences and the development of perceived control. Monographs of the Society for Research in Child Development, 63(2-3), Whole No. 204.

Skinner, E., Furrer, C., Marchland, G., \& Kindermann, T. (2008). Engagement and disaffection in the classroom: Part of a larger motivational dynamics? Journal of Educational Psychology, 100, 765-781. doi:10.1037/a0012840

Soenens, B., Sierens, E., Vansteenkiste, M., Dochy, F., \& Goossens, L. (2012). Psychologically controlling teaching: Examining outcomes, antecedents, and mediators. Journal of Educational Psychology, 104, 108-120. doi:10.1037/a0025742

Steel, P. (2007). The nature of procrastination: A meta-analytic and theoretical review of quintessential self-regulatory failure. Psychological Bulletin, 133, 65-94. doi:10.1037/0033-2909.133.1.65

Stroet, K., Opdenakker, M., \& Minnaert, A. (2013). Effects of need-supportive teaching on early adolescents' motivation and engagement: A review of the literature. Educational Research Review, 9,65-87. doi:10.1016/j.edurev.2012.11.003

Stroet, K., Opdenakker, M. C., \& Minnaert, A. (2015). What motivates early adolescents for school? A longitudinal analysis of associations between observed teaching and motivation. Contemporary Educational Psychology, 42, 129-140. doi:10.1016/j.cedpsych.2015.06.002

Taylor, I. M., \& Ntoumanis, N. (2007). Teacher motivational strategies and student self-determination in physical education. Journal of Educational Psychology, 99, 747-760. doi:10.1037/0022-0663.99.4.747

Tsai, Y., Kunter, M., Lüdtke, Trautwein, \& Ryan, R. M. (2008). What makes lessons interesting? The role of situational and individual factors in three school subjects. Journal of Educational Psychology, 100, 460-472. doi:10.1037/0022-0663.100.2.460

Vallerand, R. J., \& Bissonnette, R. (1992). Intrinsic, extrinsic, and amotivational styles as predictors of behavior: A prospective study. Journal of Personality, 60, 599-620. doi:10.1111/j.1467-6494.1992. tb00922.x

Vansteenkiste, M., Simons, J., Lens, W., Sheldon, K. M., \& Deci, E. L. (2004). Motivating learning, performance, and persistence: The synergistic effects of intrinsic goal contents and autonomysupportive contexts. Journal of Personality and Social Psychology, 87, 246-260. doi:10.1037/00223514.87.2.246

Vansteenkiste, M., Simons, J., Lens, W., Soenens, B., \& Matos, L. (2005). Examining the motivational impact of intrinsic versus extrinsic goal framing and autonomy-supportive versus internally controlling communication style on early adolescents' academic achievement. Child Development, 76, 483-501. doi:10.1111/j.1467-8624.2005.00858.x

Vansteenkiste, M., Sierens, E., Soenens, B., Luyckx, K., \& Lens, W. (2009). Motivational profiles from a self-determination perspective: The quality of motivation matters. Journal of Educational Psychology, 101, 671-688. doi:10.1037/a0015083

Vansteenkiste, M., Niemiec, C. P., \& Soenens, B. (2010). The development of the five mini-theories of self-determination theory: An historical overview, emerging trends, and future directions. Advances in Motivation and Achievement, 16, 105-165. Elsevier. doi:10.1108/S0749-7423(2010)000016A007

Vansteenkiste, M., Sierens, E., Goossens, L., Soenens, B., Dochy, F., Mouratidis, A., .. Beyers, W. (2012). Identifying configurations of perceived teacher autonomy support and structure: Associations with self-regulated learning, motivation and problem behavior. Learning and Instruction, 22, 431-439. doi:10.1016/j.learninstruc.2012.04.002

$\mathrm{Xu}$, J. (2008). models of secondary school students' interest in homework: A multilevel analysis. American Educational Research Journal, 45, 1180-1205. doi:10.3102/0002831208323276 